\title{
Recruitment and Selection Practices in Business Process Outsourcing Industry
}

\author{
Dr. Amer Hani Al-Kassem \\ City University College of Ajman -UAE \\ Chairperson of Human Recourse Management Department
}

\begin{abstract}
Regardless of company size, location or industry, one thing is certain that recruitment and selection process has become enormously challenging and complex task for human resource management function in business process outsourcing industry (BPO). Business process outsourcing organizations offer knowledge intensive services dependent on human resources for delivery and represent a cornerstone for value creation. Scholars revealed that organizations are increasingly afflicted with the issues concerning talent shortage. Moreover, it is conceivable that organizations on all ends of the spectrum might have a human resources department that is not equipped to handle difficulties such as low retention rates and exorbitant workforce turnover at their core responsibilities. All this has a significant impact on the strength and weaknesses of an organization in managing their business in a competitive environment. Therefore, this paper attempts to unveil the determinants of employment practices and understand the importance of measuring and managing employee's hope to maximize their productivity and performance. In general, BPO organizations should maintain conducive work environment and adopt motivational rewards and policies along with best of the facilities to combat employee's issues that have plagued the BPO industry.
\end{abstract}

Keywords: BPO industry, recruitment and selection practices, performance, productivity

INTRODUCTION

In the corporate world, creativity and innovations occurs rapidly due to the dynamic nature of business environment. Various organizations are concentrating on their core competencies in order to provide flexibility and improved organizational performance, and to ensure the efficient use of key resources. There is strong evidence in the literature that outsourcing has grown at a frenetic pace thus that having a bandwagon effect on many of the multinational clients. According to Kumar and Arora (2012) globalization has forced organizations outsource their production and services to countries where they find a competitive advantage in lower labor costs, improve process quality and speed time to market (Li \& Meissner, 2008). The outsourcers are mainly organizations from US and UK, they outsource the functions within administrative support, inbound call center services, technical support, sales and marketing management, human resource management and training, infrastructure facilities management, and other services (Aiswarya, 2013).

Business process outsourcing (BPO) is the common form of outsourcing. It is not a new management strategy, however has received heightened interest because of its potential economic and strategic impact. Majority of organizations in US and UK have turned to outsourcing and offshoring internal operations, not only for reasons of cost and quality, but also contracting responsibilities of specific business driver to external organizations (Ezigbo, 2012). Information processing and call center activities of service organizations have moved offshore to Asian countries in record numbers. With its ready source of English-speaking, highly educated, and technologically trained workers, has become the location of choice for 
business process outsourcing functions of multinational clients (Kripalani et al., 2003; Pio, 2007). To date, global outsourcing occurs for all types of jobs and across most industries (Gomez-Mejia et al., 2010), which is estimated that more than 3 million jobs and US\$136 billion in wages are expected. The global outsourcing market such as information technology, financial services, communication, consumer goods/services, and manufacturing is worth in excess of US $\$ 600$ billion annually, including US and UK, are unfolding in the developing world where an educated workforce is readily available (Lockwood, 2012).

In a recent research, BPO is acclaimed as "the new development model of enterprises in the new millennium" because of the output value of BPO worldwide (Li et al., 2008). The proliferation of outsourcing to new outsourced and offshored destinations such as India and the Philippines has appears poised to become major exporter of IT services resulted in robust GDP growth rates that place great demands on this emerging economic power (Dumlao, 2012; Budhwar et al., 2006). Moreover, it has created a high-velocity industry where change can be sweeping and ongoing (Srivastava, 2009). As of 2012, Philippines' IT services and BPO combined generated USD16 billion export revenue while USD20.9 billion for India. In addition, those Asian countries and their resources stand out as a salient model for bringing global workforce into unrestricted competitive approach of other country. For instance, Philippines were directly employed 926,000 full-time employees, while India has provided an estimated employment to 917,000 people (BPAP 2009-2013; Economic Times, 2013). Through these abundant results, the presence of human resources cannot be ruled out.

As employees have been ingrained and attached to external organizations, it is essential to determine factors that have high potential to influence the productivity of BPO employees involved in the expanding, high-flux outsourcing sector (Budhwar et al., 2006). Moreover, it is critical to sustain employees' productive capacity and replicate positive performance (Khandekar \& Sharma, 2006). All this has a significant impact on the strength and weaknesses of an organization in managing their business in a competitive environment. The sustainable success of BPO process depends on the uniqueness of their human resources and the systems for managing human resources effectively to become successful. Therefore, this paper attempts to unveil the determinants and understand the importance of employment practices to maximize their productivity and performance. In general, BPO organizations should maintain conducive work environment and adopt motivational rewards and policies along with best of the facilities to combat employee's issues that have plagued the BPO industry.

\section{LITERATURE REVIEW}

Despite the prosperous in exponential rate, BPO industry is ridden with inherent problems (Mehta et al., 2006) that affect the functions of human resource management. Increased globalization coupled with variations and changes in customer expectations, as well as product and knowledge intricacies make the recruitment and selection practices very difficult. People are considered to be the most valuable assets of an organization. Studies publicized that success or failure of organization is largely dependent on the caliber of the individual working therein. Without positive and creative contributions from workforce, organizations cannot progress and prosper. According to Jacobs and Roodt (2011) human resource constitutes the strategic and competitive edge in managing customer relationships as no technology can replace skilled communication, problem solving and customer focus. The choice of the right people to form a team in organization is one of the most important factors leading to its success. Hence, to achieve this, an organization has to pay a huge attention on the recruitment and selection process. Effective recruitment and selection procedures are vital in attracting and retaining high quality staff so every organization should take them deeply into consideration. Moreover, human errors are much more expensive in comparison to such assets as land and capital, and often result in serious irreversible consequences. 


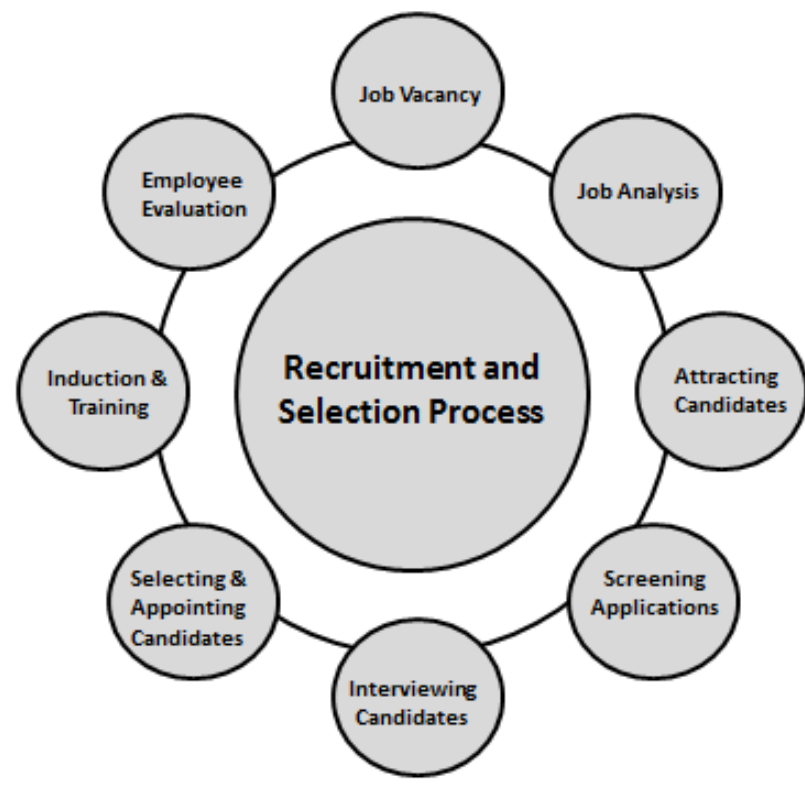

Figure 1: Recruitment and selection process Source: Failte Ireland (2013)

Recruitment and selection, as part of effective human resource management is an important function that makes it possible to acquire the number and types of people necessary to ensure the continued operation of the organization (Aiswarya, 2013). This domain is not a single, simplified function, but a group of plans, systems, tools, processes and services. Failte Ireland's (2013) recruitment and selection process, as shown in Figure 1, illustrates how each element has a contribution to make in helping to find the most suitable candidates for any advertised position and manage them in a way that maximizes their levels of engagement. Each element provides huge possibilities for profit, provided that one can use effective solutions in exploiting them. As the field of human resource management becomes more dynamics and complex, it is often claimed that selection of workers occurs not just to replace departing employees or add to a workforce but rather aims to put in place workers who can perform at a high level and demonstrate commitment (Ballantyne, 2009).

In most academic literature the terms recruitment and selection are used together, however it is necessary at the advent to elucidate the dissimilarity of the two terms as it is entirely different functions of HR. Pilbeam and Corbridge (2006) explained that those two terms is actually based on action between "applicant and job", which is dependent on stating a need by an organization, using the most appropriate techniques and on "reviewing, evaluating and modifying the recruitment and selection system in the light of experience". Recruitment is a dynamic and complex process that includes advertising a job opening to qualified applicants, enticing them to apply for the job, maintaining the candidate's interest throughout the process, and influencing their decisions until an offer is officially extended (Breaugh, 2013). It is indicates that the process of recruitment has an important purposes which is to find the best talents on the job market with professional knowledge, personal engagement and social competence. In the context of literature, new workers who came through referrals by current employees had longer tenure with the organizations that did those recruited in other ways (Taylor, 2010). A number of variables, such as the time and cost of the recruitment process, tend to have considerable influence on the expected benefits and costs of each recruitment channel. They considered employee referrals, private agencies, promotion and top notch universities as recruitment channels to hire high skilled workers (Rufini \& Torre, 2010). 
Selection is the process by which managers and others use specific instruments to choose from a pool of applicants a person or persons more likely to succeed in the jobs, given management goals and legal requirements (Bratton \& Gold, 2007). Selection is crucial and continuing function. The ability of an organization to attain its goals effectively and to develop in a dynamic environment largely depends upon the effectiveness of its selection program. If right personnel is selected the remaining functions of management becomes easier, the employee contribution and commitment will be at an optimum level and employee-employer relations will be congenial (Anoosha, 2012). Wrong decisions not only affect the various individuals associated with them, but also result to frustration, repetitive training and low morale prior to the termination of the newly hired employee. The key point of selection should be effective, efficient and fair. Fair means ensuring that the decisions made during the process is based on merit alone (ACAS, 2014). In order to reduce the risks of discrimination lawsuits, organizations should make use of fair and legal procedures which is crucial for organizational success.

In setting out a similar distinction in which recruitment activities provide a pool of people eligible for selection, Foot and Hook (2005) suggest that although the two functions are closely connected, each requires a separate range of skills and expertise, and may in practice be fulfilled by different staff members. The recruitment activity, but not normally the selection decision, may be outsourced to an agency. It makes sense, therefore, to treat each activity separately. Preethi and Rajashekar (2013) noted that while HR plays a key role in these systematic approaches, the hiring manager must be proactive and engaged in facilitating the employee's successful integration into the organization overtime. Recruitment and selection, as defined here, can play a pivotally important role in shaping an organization's effectiveness and performance, if work organizations are able to acquire workers who already possess relevant knowledge, skills and aptitudes and are also able to make an accurate prediction regarding their future abilities. Recruiting and selecting staff in an effective manner can both avoid undesirable costs. For instance, those associated with high staff turnover, poor performance and dissatisfied customers (French \& Rumbles, 2010).

\section{Issues and Challenges faced by BPO industry}

Agrawal et al. (2011) asserts that there are various challenges provided by management literature on the external organization's side. These challenges are burden of insufficient capacity, high unit personnel cost, tight business margins, not enough financial strength to sustain, very long payback periods, expensive specialist skills, compliance and legal restrictions, unavailability of skilled manpower due to market stagnation. These require considerable efforts in terms of management's time and attention to establish. Burke and Cooper (2005) found challenges of solutions provider relating to scale and scope, and integration needed to accomplish. Kim et al. (2007) emphasized that trust between service provider and receiver is important determinant in adopting BPO as outsourcing is based on trust. There are few challenges from the employees' side too. Cohen and El-Sawad (2007) discoursed about culture and cultural difference between service provider and service receiver countries.

\section{Attrition Rate}

Today, the rapid growth of BPO industry has resulted in the poaching of employees in high numbers. For instance, the number of BPO employees in the Philippines reached 900,000 in 2013 and is expected to increase to 1.3 million by 2016. Average salary of BPO employee is also increasing which would see from what it was some four years back. New development is that Philippines' BPO Industry expects to spend P247 billion ( $\$ 5.85$ billion) as salary and the forecasted revenue is $\$ 13$ billion by the end of this year. According to reports, the salaries of the outsourcing sector are equal to $14 \%$ of national government's spending program which is 
projected to be P1.86 trillion (Steve, 2012). Kumar (2008) assessed that the present salary package in BPO industry is not as lucrative as compared to other industries. However, the high attrition rate of workers paints a grim picture of the so-called 'sunshine industry' (Torres, 2014). The impact of attrition has received considerable attention by HR department. It has proven to be one of the most costly and seemingly intractable human resource challenges confronting organizations (Anantharaja, 2009; Kangaraarachchi 2010).

Various studies revealed that attrition rate in BPO firms are at the highest because of better opportunities elsewhere. Employee leaving the job is considered attrition by one organization, it is looked at as talent acquisition by the other organization and to the individual it most often means a career move, economic growth and enhancement of the quality of life. In addition, most employees works with a company in a short period of time or attrition happens in first 120 days of hiring (Radhika, 2008) due to high stress level at the job, monotonous nature of the job, loss of identity, demand-supply disparity, vague values and vision, lack of positive direction, wrong hiring policies, mismatched measures and rewards, overwork and burnout. Attrition rate is a burning issue for HR department because an organization faces problems. This is because today businesses are more dependent than ever before on their top performers to innovate and provide services that differentiate a company from its fierce competitor (Anantharaja, 2009). According to Verma and Pooja's (2011) research, the causes of attrition are different in relation to the gender. Results show that female employees feel more stressed because of work life imbalances and tend to leave jobs at an early stage of their career.

High attrition rate gives difficulties to BPO companies' bottom line. Business scholars estimate that it costs upwards of twice an employee's salary to find and train a replacement. And churn can damage morale among remaining employees. They agree that hiring the right people from the start is the single best way to reduce employee turnover. They should use psychometric tests to examine people who can work at night and handle monotony of work. Apart from that setting the right compensation and benefits is important too. Work with human resources to get current data on industry pay packages, and get creative when necessary with benefits, flexible work schedules and bonus structures. These traits will cement in the employee's minds the positive culture to be fostered in the organization. In general, organization needs to adopt a market-driven approach in dealing with the growing attrition and requires a perfect blend of time, effort, commitment and investment to craft a successful endeavor.

\section{Retention Strategies}

Every organization should understand that human capital is their best commodity. Without qualified people who are good at what they do, any organization would be in serious trouble. Retaining employees in BPO industry has been a problem in many organizations for decades. In an extremely competitive market, the HR managers have been facing a tough time in finding a suitable replacement with required experience and ability, to fill up the vacancies created on account of exit of key employees (Chordiya, 2013). A single tool like training alone is not sufficient for employee retention. The best results for employee retention can be achieved by applying different tools strategically. Employee retention, as a result, is actually concerning the culture and having the appropriate procedures for the organization to obtain the development and achievement from the organization's objectives and goals. This belief was reinforced from the investigation performed by Career Systems International in 2005, by which they detailed that high manifestation of retention strategy is connected to worker's positive behaviors causing employee to keep within the organization for that optimum time frame (Riley, 2009).

Broadly, many studies claim that there are several factors that determine an organization's ability to attract and retain employees. In Sharma's (2010) research identified some factors 
that encourages the technical pool of human resource to seek greener postures such as: better salary, transparency in expectations, accumulation value, employment security, and greater reliance on incentive pay. It is essential to protect this management approach, as talented and motivated employees play a crucial role in overall development, growth and success of the organization. Focusing on employee retention techniques can positively impact the organization; however, failing to retain a key employee is a costly proposition for an organization. It has become imperative for organizations to look into the causes of high employee attrition and come up with a strategy for there are many determinants of retention depending upon priorities and life styles of employees (Kumar \& Arora, 2012), while at the same time securing their trust and loyalty so they have less of a desire to leave in the future.

\section{Employee Communication}

Employee communication is an essential aspect of the corporate management process. This factor transformed swiftly as new social media marketing instruments which develop and influence the workplace, as the organization's culture increased the pursuits of the retention approach for employees. Distributing information and eradicating barriers enforced by variations in area or divisions within the organization through technological innovation can build employee communication (Ghafoor et al., 2012). It is among the most powerful indications of employee empowerment within an organization. Despite the fact employees are frequently bombarded by having an avalanche of information, they continue to participate in upward interaction within a provided work situation and undertaking a well-mannered mindset towards the individuals at all times. In a connection to marketing group, employee is the conduit to customers as well as to the outside community. If business objectives and messages in the organizations are evidently recognized, employee can serve as valuable ambassadors (Miles \& Mangold, 2005).

Within the framework of management style, employee communication is needed when working with individual in various areas of career. It is a significant device in building relationships in more subtle ways. For example, getting responses and maintaining genuine communications would be the hallmarks of employee retention technique. Top management and managers attain those desired goals by means of regular meetings and survey that may shed light on why employees think about leaving. Through interviews with disaffected employees, organizations could work to give further attention to the needs, difficulties and grievances of employees including with the rewards system (Nyamekye, 2012). By taking a chance to pay attention organizations develop and create a culture of commitment that minimizes the potential risk of turnover. However, one of the primary sources of work environment anxiety is an absence of information particularly during times of change. It is often assumed that selections created at the top management are being conveyed down from the ranks. As a result, innovator or director must guarantee to provide excellent and precise details of information in a timely manner that contributes to productivity and employee retention (Guo \& Sanchez, 2005).

\section{Organizational Culture}

Organizational culture is a critical element of organizational life. It has been presented as buzzword which signifies the attention of management scholars across the globe for at least two decades. According to Pandita (2011) culture is an existing resource resist to impart business knowledge to vendor's resources due to fear of losing jobs leading to gaps in knowledge capture. Obviously employees working in the BPO industry sacrifice their lives in various ways. The geographical time difference with the European countries gives the industry one of the biggest advantages. As a result employees have to work in nights for long working hours and travel time, which creates lot of stress and unhealthiness. And because of stressful life in BPO environment, employees are difficult to express precious time for their families. This issue becomes more complicated and problematic when they get married. Thus, these 
extra responsibilities to be given to the family, most employees quit the job. In addition to the above, one of the other major social problems that arises in the BPO industry is the cultural issues because of working with the western world. Personal habits and disciplines have undergone a considerable change due to western culture (Business Teacher, 2015).

Studies showcased that cultural alignment matters in both customer service delivery and selecting customer service partners. In a recent report, the role of right culture gives advantage among companies providing similar service. However, there is no size fits all for creating great company culture. For instance, an influential industry event in June 2014, the Call Center Week held in Last Vegas, TELUS International and GOOGLE shared similar values and beliefs in retaining and motivating the best people to deliver excellent customer service. Those values are for treating one another as family members and working as a community not just a company, investing in the personal and professional development of people to stimulate innovation, and having higher purpose and making an impact that will change the world. They believe that creating strong culture that resonates with employees' and the organization's values would result in exceptional customer service (TELUS International, 2015). In fact, these shared philosophies, articulated values, beliefs, and behaviors contribute to the unique social and psychological environment of an organization. In general, organizational culture is the 'glue' that guides behavior and design organizational decision-making (Haberberg \& Rieple, 2008), and the lack of this glue will bring about devastating consequences around the organization.

\section{Global Economic Turmoil}

A global recession is a period of global economic slowdown. The International Monetary Fund (IMF) takes many factors into account when defining a global recession, it states that global economic growth of $3 \%$ or less is equivalent to a global recession (Economist, 2008; Lall, 2008). The recession in the US market and the global meltdown termed as Global recession have engulfed complete world economy with a varying degree of recessional impact. World over the impact has diversified and its impact can be observed from the very fact of falling Stock market, recession in jobs availability and companies following downsizing in the existing available staff and cutting down of the perks and salary corrections. The global financial crisis has its origins in the U.S. subprime mortgage crisis of August 2007. It seemed initially that it would only affect developed countries, but the so-called "decoupling phenomenon," which predicted that developing countries would remain unaffected, has not occurred. Instead the crisis has become a global phenomenon (Kumar, 2011).

The turmoil of global economy caught the attention of many experts and debates on how it will adversely affect business process outsourcing (BPO) companies. For instance, there has been a twin movement that has manifested itself in the way the BPO sector has been impacted. Many companies in US and UK have trimmed their budgets and have reduced their outsourcing exposure significantly. There has been an uptick in the way in which some companies have increased the pace of outsourcing. Though these twin imperatives might seem contradictory and conflicting, there are reasons for this kind of behavior. Many companies that have suffered because of the ongoing global economic crisis and have not received assistance from the government have decided to curtail the outsourcing budgets whereas others who have been bailed out by the government have decided to increase outsourcing as a means of cutting costs. The point here is that the companies in the West that have preferred to lay off their employees at home and instead ship jobs overseas are the ones that have increased business for the BPO sector. And those companies that have preferred to retain their domestic workforce are the ones that have increased the pace of outsourcing (MSG Team, 2014). 
Goel and Thakur (2007) states that India as one of "destination of choice" for BPO market has been affected of global economic meltdown. But companies are seeing an opportunity in these adverse times. Industry players believe that the ability to grow up the value chain and also the emergence of some new businesses will see Indian companies emerging stronger in 2009, despite uncertainties in the markets that bring most of their revenues. In connection to this, companies should view this time as an opportunity to acquire new clients and tap fresh business. Expansion of client database amongst various international markets would only serve to insulate the companies against impact of downturn in respective economies. Moreover, it is the time to improvise and update the basic drivers for outsourcing decision making in the businesses (Hagan, 2013).

\section{Decision-Making Framework of BPO}

Various theories have been coined in the academic literatures that support the decisionmaking framework of outsourcing business functions. It provides insights about the past, describes the current landscape and predicts the future outlook. These frameworks serve as theoretical background for making decisions. However, it could vary from cost basis to internal growth. In management arsenal, some studies have developed a theoretical framework from which outsourcing decisions can be made. These include value chain framework and transaction cost economic (Kennedy et al., 2013). A study conducted by Dibbern and Heinzl (2009) on decision-making for outsourcing in small and medium sized enterprises served as a theoretical framework. The results show that internal performance and know-how deficits vis-à-vis external service providers are key determinants. Borman (2005) also presented with a third theory of decision-making basis for outsourcing which is resource dependency theory.

Within the management framework, these theories helped to determine the objective or motivation for deciding to practice BPO. Both theories help to understand why work has moved offshore and which types of activities provide the higher potential for offshore value creation. It delineates the macro-trends that have driven and continue to drive the rapid growth of the BPO industry. These theories illustrate the potential for firms to create value by choosing to outsource certain activities. Helps demonstrate that for a firm to create value and maintain its competitive position, it should focus only on a few core activities that add value and consider alternatives like outsourcing for non-core activities (Kennedy et al., 2013).

\section{Value Chain Framework}

Understanding the complexities of global production is a challenging task. In a world of offshoring, outsourcing and vertical specialization, activities of firms are spread across countries and national statistics cannot fully account for international production. A value chain can be simply defined as the "full range of activities that firms and workers do to bring a product from its conception to its end use and beyond" (Gereffi and Fernandez-Stark, 2011). According to Porter's (2001) research, that a firm is a system of interconnected activities, and a firm's competitive advantage depends upon how well it performs (or extracts value from) those activities. Typically, a value chain includes the following activities: design, production, marketing, distribution and support to the final consumer. These activities can be performed within the same firm or divided among different firms.

For offshore services industry, measuring value is complicated by the lack of reliable company level data and trade statistics for services (Sturgeon \& Gereffi, 2009). To partially address this problem, the value of different services can be related to employee education level and work experience (Gereffi \& Fernandez-Stark, 2010). By indicating the human capital required at different levels of the offshore services value chain, this classification provides decision makers in developing countries with an instrument to determine where they may be best suited to 
enter the value chain in order to achieve their desired outcomes. It also provides an initial blueprint for economic upgrading strategies within the industry. Developing countries that aim to provide services within certain segments of the value chain must evaluate their workforce development strategies and implement policies to build human capital for those segments. In general, firms should strive to understand not only their value chain operations, but also their competitors, suppliers and distributors value chains (Odhiambo, 2010).

\section{Transaction Cost Economic}

The second theory, which is the transactions cost theory, states that external or internal provision is decided on the basis of a cost comparison with regards to the sum of transaction and production costs. Transaction costs were defined as all costs of planning, adapting, and monitoring task completion within the individual functions under alternative governance modes. The concept of transaction costs is to explain the organization of firms and the method of their interactions by providing a conceptual framework for investigating some of the organizational challenges and economic risks that firms face (Garfamy, 2013). A variety of changes in the business environment, including global competition, international cooperation, and vertical disintegration, along with a focus on core competencies, have fueled interest of economists and politicians to help an organization determine where an activity should take place inside or outside the firm.

Transaction costs fall into three broad categories: (i) search and information costs are incurred when a firm starts searching for information about goods or services in the marketplace to determine their availability and price. For example, search costs are incurred when a firm is searching for a vendor in a distant country; (ii) bargaining costs are incurred during the negotiation phase. Before an agreement is accepted by both firms, costs related to travel and communication as well as legal and consulting fees are incurred by both parties. For example, a service level agreement (SLA) is created when entering into a relationship with an offshore vendor. Such agreements can be very detailed and costly to develop; (iii) and policing and enforcement costs are incurred to ensure that the other party acts according to the terms of a contract (Kennedy et al., 2013). Thus, the decision to embark on outsourcing a particular business function should stem from the comparatively lower costs that will be incurred if an external vendor is consulted. Companies assume they will save money when they decided to outsource to a foreign provider. Moreover, the cost savings must be significant (Coward, 2003).

\section{Resource Dependency Theory}

The resource dependency theory refers to how organizations depend on their external environment to make choices on managing their dependency on these environmental factors. It has been under scrutiny in several review and meta-analytic studies which all indicate and discuss the importance of this theory in explaining the actions of organizations, by forming interlocks, alliances, joint ventures, and mergers and acquisitions, in striving to overcome dependencies and improve an organizational autonomy and legitimacy (Hillman et al., 2009; Davis and Cobb, 2010; Drees \& Heugens, 2013; Sharif \& Yeoh, 2014). Pfeffer (2003) asserts that resource dependency theory was developed to understand precisely the type of interorganizational relations that have played such a large role in recent 'market failures'. The motivation of those running the organization was to ensure the organization's survival and to enhance their own autonomy, while also maintaining stability in the organization's exchange relations. These were the drivers behind many of the organization's observed actions.

Moreover, when it came to explaining strategy, power often trumped profits, an insight distinctly at odds with the dominant economic approaches of the time. There are three core 
ideas of the theory: (1) social context matters; (2) organizations have strategies to enhance their autonomy and pursue interests; and (3) power (not just rationality or efficiency) is important for understanding internal and external actions of organizations. The emphasis on power, and a careful articulation of the explicit repertoires of tactics available to organizations, is a hallmark of resource dependence theory that distinguishes it from other approaches, such as transaction cost economics (Davis and Cobb, 2009). For a company to depend on one firm to be a sole provider of their outsourcing needs, they should look at certain resources that the external firm has that show their capabilities to perform as an outsourcing firm like physical infrastructure, technical infrastructure, project management skills, and quality certification and critical mass of skilled technical professionals (Coward, 2003). All these factors are external resources that companies are required to make outsourcing decisions.

\section{CONCLUSION}

Business Process Outsourcing industry has witnessed growth with an unparalleled velocity. Despite the momentous growth and brilliant future, the BPO industry has facing a lot of challenges such as unavailability of skilled employees, attrition, retention of suitable employees, global economic slowdown. They should try hard to resolve these issues and challenges through various innovative measures in managing human resources. As human resources is an important corporate asset and the overall performance of companies depends upon the way it is put in use. A firm's resources propel it towards its goals, just as an engine propels an automobile towards its destination (Bratton and Gold, 2008). Acquiring their services, developing their skills, motivating them to high levels of performance, and ensuring that they maintain their commitment to the organization are essential to achieving organizational objectives. No organization can survive without the giving importance to its employee. They are the first customers and their requirement should be identified and fulfilled. Moreover, adopting different business models, best practices and strategies are the mantra an organization should follow to retain their employees. Fulfilling the reasonable expectations of employees should be a continuous process. In general, BPO companies need to give themselves a broad canvas to follow for any possible chance for innovation that may end up creating high business worth for customers.

\section{References}

ACAS (2014). Recruitment and Induction. Retrieved March 2014, from http://www.acas.org.uk/media/pdf/8/d/Recruitment-and-induction-advisory-booklet.pdf

Agrawal, S., Goswami, K., \& Chatterjee, B. (2011). Challenges of ITES Companies in India. International Journal of Humanities and Social Science 1(2): 218-226.

Aiswarya, M. (2013). A Study on Effectiveness of Recruitment Process in HCL Technologies - BPO Chennai. International Journal of Management, 4(3): 14-18.

Anantharaja, A. (2009). Causes of Attrition in BPO Companies: Study of a Mid-Size Organization in India. The IUP Journal of Management Research, 8(11): 13-27.

Anoosha, M. (2012). A Study on Importance of Recruitment and Selection Process at Manasi Systems Technologies Pvt. Ltd (Master's thesis). Gokaraju Rangaraju Institute of Engineering and Technology, Hyderabad, IN.

Ballantyne, I. (2009). Recruiting and selecting staff in organizations. In S. Gilmore and Williams, S. (eds) Human Resource Management, Oxford: Oxford University Press.

Borman, M. (2005). A decision making framework for information technology enabled business process outsourcing. Pacific Asia Conference on Information Systems (PACIS 2005) Proceedings, Paper 53.

Bratton, J., \& Gold, J. (2007). The human resource management arena. In: J. Bratton \& J. Gold (Eds.), Human resource management: Theory and practice (4th edition), (pp.1-72). Hampshire, UK: Macmillan. 
Bratton, J., \& Gold, J. (2008). Human Resource Management Theory and Practice, Pal Grave Macmillan Publication, $3^{\text {rd }}$ edition, New York.

Breaugh, J. A. (2013). Employee recruitment. Annual Review of Psychology, 64, 389-416.

Budhwar, P. S., Varma, A., Singh, V., \& Dhar, R. (2006). HRM systems of Indian call centers: An exploratory study. International Journal of Human Resource Management, 17(5): 881-897.

Burke, R. J., \& Cooper, C. L. (2005). Reinventing Human Resource Management: Challenges and New Directions. London \& New York: Routledge.

Business Processing Association of the Philippines (BPAP). 2009-2013. Breakthroughs newsletter (various issues). (http://www.bpap.org).

Business Teacher (2015, January 2). Benefits and Challenges of the IT BPO Industry. Retrieved from http://www.businessteacher.org.uk/essays/business/benefits-and-challenges-of-the-it-bpo-industry.php.

Chordiya, K. D. (2013). Retention Strategies With Reference to BPO Sector. In Proceedings of 1st National Conference on "Dynamism in Management" Special Issue of International Journal of Engineering, Economics and Management, pp. 26-30.

Cohen, L., \& El-Sawad, A. (2007). Lived Experiences of Offshoring: An Examination of UK and Indian Financial Service Employees' accounts of themselves and one another. Human Relations, 60(8): 1235-1262.

Combs, G. M., Clapp-Smith, R., \& Nadkarni, S. (2010). Managing BPO Service Workers in India: Examining Hope on Performance Outcomes. Human Resource Management, 49(3): 457-476.

Coward, C. T. (2003). Looking Beyond India: Factors that shape the Global Outsourcing Decisions of Small and Medium Sized Companies in America. The Electronic Journal of Information Systems in Developing Countries. Retrieved from http://www.ejisdc.org.

Chandrasekar, K. (2011). Managing Attrition: The Real Problem Behind the Growth of Business Process Outsourcing (BPO) Companies. Journal of Social Welfare and Management, 3(1): 27.

Davis, G. F., \& Cobb, J. A. (2009). Resource Dependency Theory. Research in the Sociology of Organizations, pp. 131.

Davis, G. F. and J. A. Cobb (2010) "Resource dependence theory: Past and future." Stanford's organization theory renaissance, 1970-2000: 21-42. Bingley, NY: Emerald Group.

Dibbern, J. \& Heinzl, A. (2009). Outsourcing of Information Systems Functions in Small and Medium Sized Enterprises: A Test of a Multi-Theoretical Model. Business \& Information Systems Engineering, 1(1):101-110.

Drees, J. M. and P.P.M.A.R. Heugens (2013). "Synthesizing and Extending Resource Dependence Theory: A MetaAnalysis." Journal of Management, 39: 1666-1698.

Dumlao, D. (2012). IT-BPO Revenue reached $\$ 11$ billion in 2011. Philippine Daily Inquirer. Retrieved from http://business.inquirer.net/53163/it-bpo-revenue-reached-11b-in-2011.

Economic Times (2013). BPO sector exports expected to have reached \$17.8 billion: Milind Deora. Retrieved from http://articles.economictimes.indiatimes.com

Economist (2008, October 9). The World Economy: Bad or Worse. Economist.Com. Retrieved from http://www.economist.com/node/12381879.

Ezigbo, C. A. (2012). Justification of Outsourcing for Organization's Competitive Advantage. European Journal of Social Sciences, 34(2): 262-272.

Failte Ireland (2013). Recruitment and Section: A guide to help you review your existing approach to recruitment and selection. Retrieved from http://www.failteireland.ie

Foot, M., \& Hook, C. (2005). Introducing Human Resource Management, Fourth Edition, England, Prentice Hall.

French, R., \& Rumbles, S. (2010). Recruitment and Selection. In Rees, G., \& French, R. (Ed.), Leading, Managing and Developing People, $3^{\text {rd }}$ edition (pp. 169-190). CIPD: UK.

Garfamy, R. M. (2013). Supply Management: A Transaction Cost Economics Framework. South East European Journal of Economics and Business, 7(2): 139-147. 
Ghafoor, M., Martin, T., \& Choo, E. S. (2012). Six ways social media technologies can accelerate large-scale change. Outlook point of view, 1: 1-2.

Gereffi, G., \& Fernandez-Stark, K. (2010). The Offshore Services Industry: A Global Value Chain Approach. Durham: Center on Globalization Governance and Competitiveness - Duke University. Commisioned by CORFO.

Gereffi, G. and K. Fernandez-Stark (2011). “Global Value Chain Analysis: A Primer”, Center on Globalization, Governance \& Competitiveness (CGGC), Duke University, North Carolina, USA.

Goel, D., \& Thakur, P. (2007). India: An Attractive BPO Destination Marred By Alarming Attrition [White Paper]. Retrieved from http://www.tpi.net/pdf/papers/tpi_whitepaper_india.pdf

Gomez-Mejia, L. R., Balkin, D. B., \& Cardy, R. L. (2010). Managing Human Resources, PHI Learning Pvt. Ltd., New Delhi.

Guo, K. L., \& Sanchez, Y. (2005). Workplace communication. In N. Borkowski (Eds.), Organizational Behavior in Health Care (pp. 77-105). Sudbury, MA: Jones and Bartlett Publishers.

Haberberg, A., \& Rieple, A. (2008). Strategic management: Theory and application, Oxford University Press, New York, NY.

Hagan, N. A. (2013). A study of the relationship between company size and business process outsourcing in manufacturing companies in Ghana. Unpublished Thesis, Ashesi University College, Ghana: Ghana.

Hillman, A. J., Withers, M. C. and B. J. Collins (2009). "Resource dependence theory: A review." Journal of Management 35: 1404-1427.

Jacobs, C., \& Roodt, G. (2011). A Human Capital Predictive Model for Agent Performance in Contact Centres. SA Journal of Industrial Psychology, 37(1): 1-19.

Kangaraarachchi, R. (2010). Interview by Fernando, S, „Lanka heading to be more service oriented now' - H R Leader, Daily News, 08 September.

Kennedy, R., Sheth, S., London, T., Jhaveri, E., \& Kilibarda, L. (2013). Impact Sourcing: Assessing the Opportunity for Building a Thriving Industry. Retrieved from http://www.rockefellerfoundation.org.

Khandekar, A. \& Sharma, A. (2006). Organizational Learning and Performance: Understanding the Indian Scenario in Present Global Context. Education \& Training, 48(8): 682-692.

Kim, J. J., So, S. H., \& Lee Y. H. (2007). The Effects of Trust on the Intention of Adopting Business Process Outsourcing: An Empirical Study. International Journal of Computer Science and Network Security, 7(10): 118123.

Kripalani, M., Engardio, P., \& Hamm, S. (2003). Cover story: The rise of India. Business Week, 3861, 66-76.

Kumar, N. A. (2011). Impact of Global Recession on Indian IT Industry and Effectiveness of E-Business in the Era of Recession. Global Journal of Business Management and Information Technology, 1(1): 9-25.

Kumar, V. (2008). High Attrition rate attributed to pay package, Online Article Retrieved from

http://outsourceportfolio.com/high-attrition-rate-attributed-to-pay-package on September 7, 2009.

Kumar, R. \& Arora, R. (2012). Determinants of Talent Retention in BPO Industry. The Indian Journal of Industrial Relations, 48(2): 259-273.

Lall, S. (2008, April 9). IMF Predicts Slower World Growth Amid Serious Market Crisis. International Monetary Fund.

Li, H. \& Meissner, J. (2008). Improving Quality in Business Process Outsourcing through Technology, Working Paper. Lancaster University Management School.

Li, H., Chang, J., \& Dong, M. (2008). Location selection of BDO vendors based on a game theory model. Human Systems Management, 27: 313-320.

Lockwood, J. (2012). Are We Getting the Right People for the Job? A Study of English Language Recruitment Assessment Practices in the Business Processing Outsourcing Sector: India and the Philippines. Journal of Business Communication, 49(2): 107-127.

Management Study Guide (2014, December 31). Effect of the Global Financial Crisis on the BP0 Sector. Retrieved from http://www.managementstudyguide.com/effect-of-global-financial-crisis-on-bpo.htm 
Mehta, A., Armenakis, A., Mehta, N., \& Irani, F. (2006). Challenges and Opportunities of Business Process Outsourcing in India. Journal of Labor Research, 27(3): 323-338.

Miles, S. J, \& Mangold, W. G. (2005). Positioning Southwest Airlines through employee branding. Business Horizons, 48: 535-545.

Nyamekye, F. (2012). Impact of motivation on employee retention: A case study of standard chartered bank Ghana limited (Master's thesis, Institute Of Distance Learning, Kwame Nkrumah University of Science and Technology). Retrieved from http://dspace. knust.edu.gh

Odhiambo, O. A. (2010). The Value Chain Analysis in Telkom Kenya [Master's thesis]. University of Naroibi, Kenya.

Pandita, K. (2011, April 25). The BPO and Offshoring Best Practices Forum: What are the top five challenges in bpo transitions that still need to be addressed in outsourcing/offshoring industry? [Linkedin]. Retrieved from https://www.linkedin.com/groups/what-are-top-five-challenges-99434.S.51711676

Pfeffer, J. (2003), "Introduction to the classic edition," in Pfeffer, J. and Salancik, G. R., The External Control of organizations: A Resource Dependence Perspective (classic edition), Stanford University Press, Stanford, CA.

Pilbeam S., \& Corbridge, M. (2006). People Resourcing: Contemporary Human Resource Management in Practice, Third Edition, Prentice Hall/Financial Times: Harlow.

Pio, E. (2007). HRM and Indian epistemologies: A Review and Avenues for Future Research. Human Resource Management Review, 17(3): 319-335.

Preethi, K., \& Rajasekhar, T. (2013). The Significance of On-Boarding Process in Work Dimensions. Research Journal of Management Sciences, 2(9): 7-11.

Radhika (2008). 40 percent attrition happening in 120days. Online article Retrieved from www.mckinsey.com/clientsservice/bto/../pdf accessed on 23rd February 2009.

Riley, J. (2009, October 1). Economy No Deterrent; You a Retention Plan. Retrieved from http://www.bcaaz.com.

Rufini, A. \& Torre, D. (2010). Choosing recruitment channels to fill high job positions. International Journal for Talent Management, 1-33.

Sharif, S. P. and Yeoh, K. K. (2014). "Independent Directors' Resource Provision Capability in Publicly-listed Companies in Malaysia." Corporate Ownership and Control 11(3): 113-121.

Sharma, S. (2010). Retention Strategies in ITES-BPO Industry, viewed 5 October 2010 from http://www.bpoindia.org/research/retentionstrategies-call-center-industry.shtml

Steve (2012). Average salary of BPO employee in Philippines in 2012 at $\$ 9,182$. Retrieved from http://www.bpmwatch.com.

Sturgeon, T., \& Gereffi, G. (2009). "Measuring Success in the Global Economy: International Trade, Industrial Upgrading, and Business Function Outsourcing in Global Value Chains." Transnational Corporations, 18(2): 1-35.

Taylor, S. (2010). The relationship between sources of new employees and attitude towards job. The Journal of Social Psychology, 134(1): 99-110.

TELUS International (2015, January 2). Google and TELUS Share Insights on the Role of Culture in Leveraging BPO Partnerships and Customer Service. Retrieved from http://telusinternational-europe.com.

Torres, E. (2014). Philippines: A Magna Carta for Call Centre Workers. Equal Times. Retrieved from http://www.equaltimes.org.

Vermin, A., \& Pooja, G. (2011). Work is to Balance Life and Life is to Balance Work: A Comparative Study.

Business and Management: Contemporary Research Issues, Macmillan Publishers India Ltd., New Delhi: 102-109. 